\title{
Effect of number of transects and identification hauls on acoustic biomass estimates under mixed species conditions
}

\author{
Jacques Massé and Nathalie Retière \\ IFREMER, Laboratoire d'Écologie halieutique, DRV-RH, B.P. 1105, 44311 Nantes Cedex 03, France.
}

Received March 23, 1995; accepted April 4, 1995.

Effets du nombre de radiales et de chalutages sur l'évaluation acoustique de la biomasse dans le cas de peuplements multispécifiques.

Massé J., N. Retière. Aquat. Living Resour., 1995, 8, 195-199.

\section{INTRODUCTION}

Estimating fish abundance by species from acoustics requires, first, an accurate measure of the total echo energy backscattered by the fishes in the area of interest and, second, an estimate of the relative contribution of the different species. Because of the difficulty to split the total acoustic biomass into species, the classification of fish schools or species assemblages has always been a predominant concern (Cushing, 1977; Johanesson and Losse, 1977; Gerlotto, 1993; Rose and Leggett, 1988; Scalabrin and Massé, 1993; Weill et al., 1993), but no satisfactory method is presently available. Therefore, for mixed populations, trawl samples are used to determine the proportion of the total echo energy due to each species and their size composition to compute specific relative abundance indices (MacLennan and Simmonds, 1992). The present paper investigates the effect of the number and location of trawl samples and acoustic transects on these estimates of abundance by species.

\section{MATERIAL AND METHODS}

A 48-h acoustic survey was conducted in April 1992 in southern Bay of Biscay in south-west France (fig. 1). Eight transects were prospected in a 64 square-mile area. These transects were 8 nautical miles long and separated by one nautical mile. Species composition was provided by 8 pelagic hauls (one for each transect) ( fig. 1). During a previous investigation which occurred 10 days earlier, shoals composed of almost $100 \%$ anchovy (Engraulis encrasicolus) were observed in this small study area as a thick layer close to the bottom. West of this area, mackerel (Scomber scombrus) and horse-mackerel (Trachurus trachurus) were present and sardine (Sardina pilchardus) and sprat (Sprattus sprattus) were closer to the coast on the east. During this second investigation, after bad weather, these latter species were mixed with anchovy, and all acoustic detections were scattered in the whole area as small shoals from the bottom and up to 20 meters. This new configuration with several species was a good opportunity to test the sampling method (transects and hauls).

The vessel was equipped with a single beam echo-sounder, OSSIAN $1500(38 \mathrm{kHz})$ with a TVG amplification of $20 \log \mathrm{R}$ and an hull-mounted transducer (SIMRAD, $13^{\circ} \times 8^{\circ}$ ). Acoustic data were collected with the acquisition and processing system INES/MOVIES (Diner et al., 1990; Weill et al., 1993), using a 12-bit A/D converter sampling at $7.5 \mathrm{kHz}$, which corresponds to a $10 \mathrm{~cm}$ vertical resolution. The pulse duration was $1 \mathrm{~ms}$. 


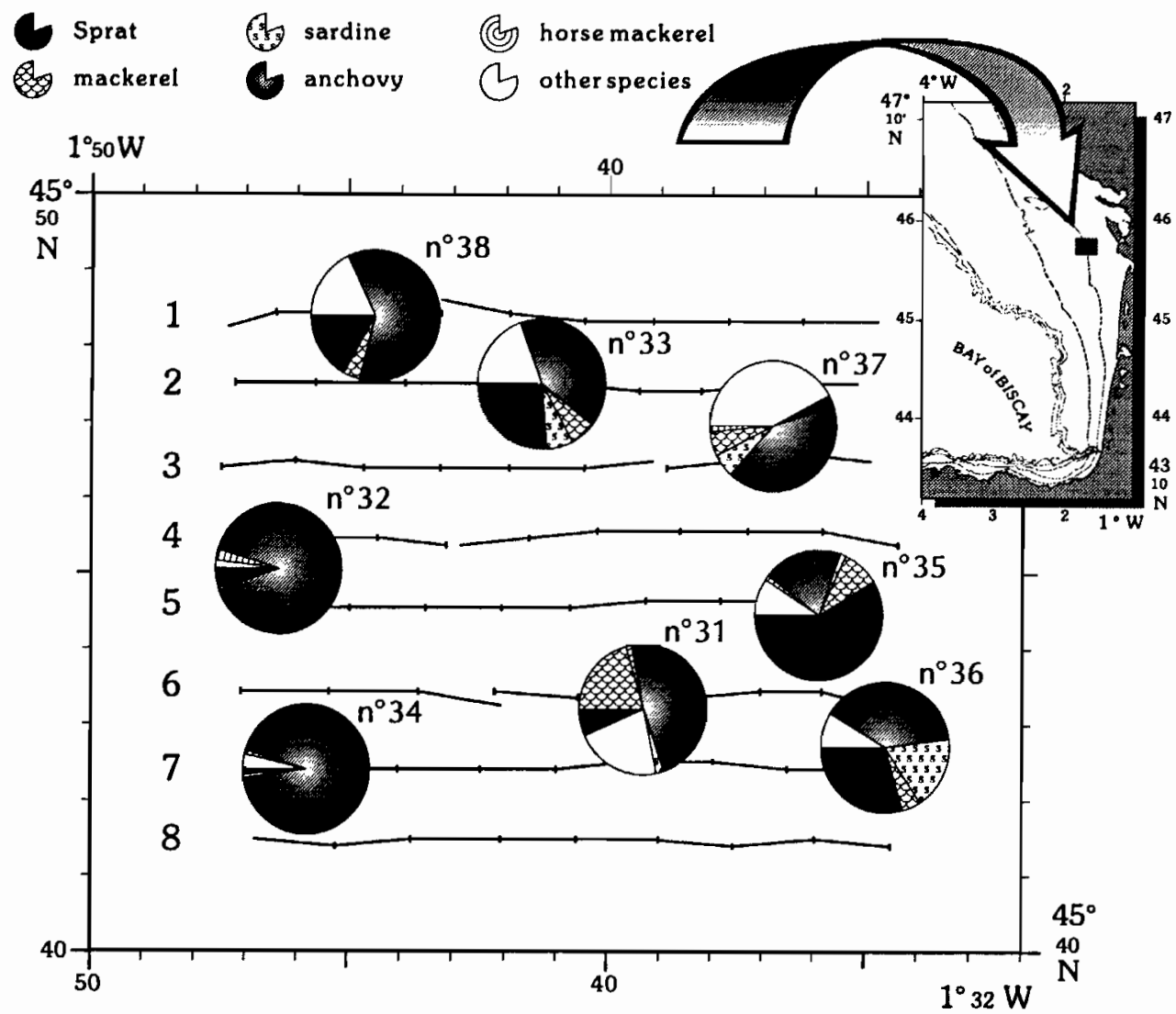

Figure 1. - Study area in the Bay of Biscay. Hauls are represented by piecharts which indicate the species compositions in percentage according to the corresponding catches. Segments represent acoustic integration units (e.g. samples).

A comparison between different combinations of transects and/or pelagic hauls was possible, because the short prospecting time ( $48 \mathrm{~h}$ ) of the study area and because acoustic and fishing data were both collected during day-time. Six different systematicsampling estimates were calculated from these data, using two, three, four or eight transects and their corresponding hauls (table 1). The biomass estimates for the different combinations and their respective coefficients of variation were calculated using species composition of the trawl samples for allocating the echo-integration values to the species. According to Diner (1983) and Massé (1988), these species compositions were previously weighted by the fish density observed at the fishing location as follows:

Table 1. - Combinations of transects and hauls of figure 1 used to compute the systematic-sampling estimates of table 2 .

\begin{tabular}{llll}
\hline Combination & Transects & \multicolumn{1}{c}{ Hauls } \\
\hline C.1 & 1 to 8 & all 8 hauls \\
C.2 & $1,3,5,7$ & & $38,37,35,34$ \\
C.3 & $2,4,6,8$ & & $33,32,31,36$ \\
C.4 & $1,4,7$ & $38,32,34$ \\
C.5 & $2,5,8$ & $33,35,36$ \\
C.6 & 2,7 & 33,34 \\
\hline
\end{tabular}

With this objective, a weighting factor $\mathrm{X}_{a i}$ was calculated for each haul and each species:

$$
\mathrm{X}_{a i}=\mathrm{P}_{a} / \sum_{k=1}^{n}\left(\mathrm{P}_{k} / \mathrm{C}_{k}\right)
$$

where $n$ : number of species present in haul $i$ $\mathrm{P}_{a}$ : catch proportion for species $a$ in haul $i$

$\mathrm{C}_{a}$ : acoustic factor (in tons/square nautical mile/acoustic unit) (MacLennan and Simmonds, 1992) calculated from the sounder parameters and the acoustic target strength (T.S.) and mean length (L) relationship for the species $a$ :

Clupeidae (Anon., 1983) T.S. $=20 \log \mathrm{L}-71.2$ horse mackerel (Vorobyov and Ivanov, 1981)

T.S. $=20 \log \mathrm{L}-68.7$ mackerel (Edwards and Armstrong, 1983)

$$
\text { T.S. }=20 \log \mathrm{L}-82.0
$$

other species (Gadidae) (Foote, 1980)

$$
\text { T.S. }=20 \log \mathrm{L}-67.0
$$

Then a mean coefficient $X_{a m}$ was calculated for each species and each combination, taking into account 
the respective $X_{a i}$ weighted by the acoustic energy observed at the fishing location.

Then a mean coefficient $X_{a m}$ was calculated for each species and each combination, taking into account the respective $\mathrm{X}_{a i}$ weighted by the acoustic energy observed at the fishing location.

$$
\mathrm{X}_{a m}=\frac{\sum_{i=1}^{n} \mathrm{X}_{n i} \cdot \mathrm{m}_{\imath}}{\sum_{i=1}^{n} \mathrm{~m}_{\imath}}
$$

The biomass estimates for each species $\left(B_{a}\right)$ was thus calculated:

$$
\mathrm{B}_{a}=\mathrm{X}_{a m} \cdot \mathrm{S} \cdot \mathrm{D}
$$

where $S$ is the area (square nautical miles) and D is the mean acoustic energy (acoustic units) observed at the study area.

Thus a variance is calculated from the ratio estimate (Cochran, 1977) by:

$$
\begin{aligned}
\operatorname{Var}\left(\mathrm{B}_{a}\right)= & \mathrm{S}^{2} \cdot \mathrm{D}^{2} \cdot \frac{1}{n(n-1) \bar{m}^{2}} \\
& \cdot \sum_{i=1}^{n}\left(\mathrm{X}_{a z} \mathrm{~m}_{i}-\mathrm{m}_{i} \mathrm{X}_{a m}\right)^{2}
\end{aligned}
$$

where $\mathbf{m}_{i}$ is the mean acoustic energy observed in the neighbourhood of haul $i$ location, and $\mathrm{m}$ the average of $\mathrm{m}_{i}$ at the study area. The coefficient of variation which is derived from the mean (1) and the variance (2) estimators reflects the heterogeneity of the species distribution in an area since they are based on the catches and the density of fish observed by acoustics.

\section{RESULTS AND DISCUSSION}

\section{Combination of transects and pelagic hauls (figs. 2 and 3)}

The mean acoustic energy and total biomass do not change much with the number of transects (from 1.489 to 1.756 acoustic units, and from 2484 to 2983 tons respectively) but the calculated biomasses per species vary significantly from one combination to another (anchovy from 968 to 2542 tons; sardine from 17 to 245 tons). The estimates are therefore very dependent on identification hauls.

The combinations 1, 2, 3 and 6 (2, 4 and 8 hauls) give similar results, indicating that the number of hauls does not have a great effect on the estimate. On the other hand, combinations 4 and 5 ( 3 hauls), show very different results. Figure 1 shows that the hauls in combinations $1,2,3$ and 6 , were well distributed throughout the area. On the contrary, hauls used in combinations 4 and 5 ( fig. 1) are located in the west and east part respectively of the study area, and had very different species compositions, 60 to $90 \%$ of anchovy compared to less than $50 \%$. From these distributions, combination 4 provided a higher anchovy biomass estimate than combination 5 . Despite the difference in biomass estimates we can see that the mean coefficient of variation increased when the number of hauls decreased (fig.3), but

(a.u.)

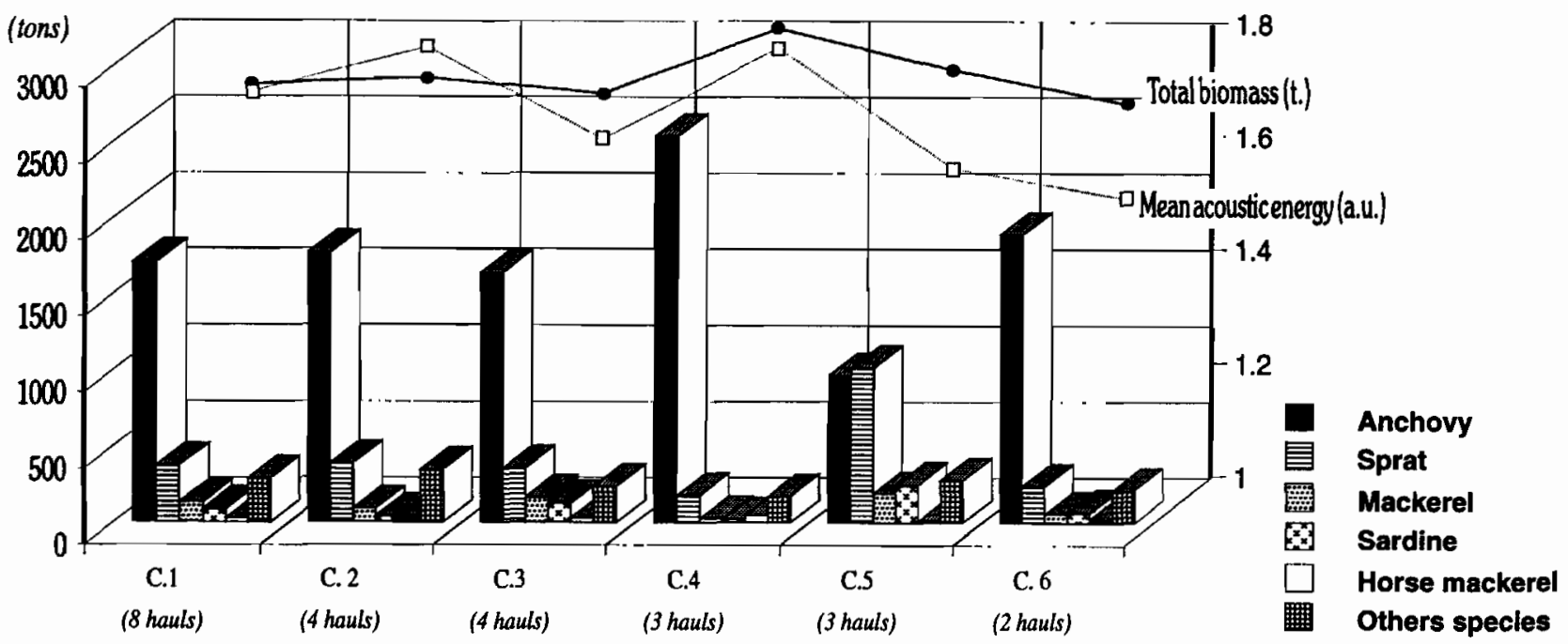

Figure 2. - Estimates of total biomass ( $t$ ), mean acoustic energy (acoustic units) and abundance index for each species (solid bars) as calculated for each combination of havls and transects. 


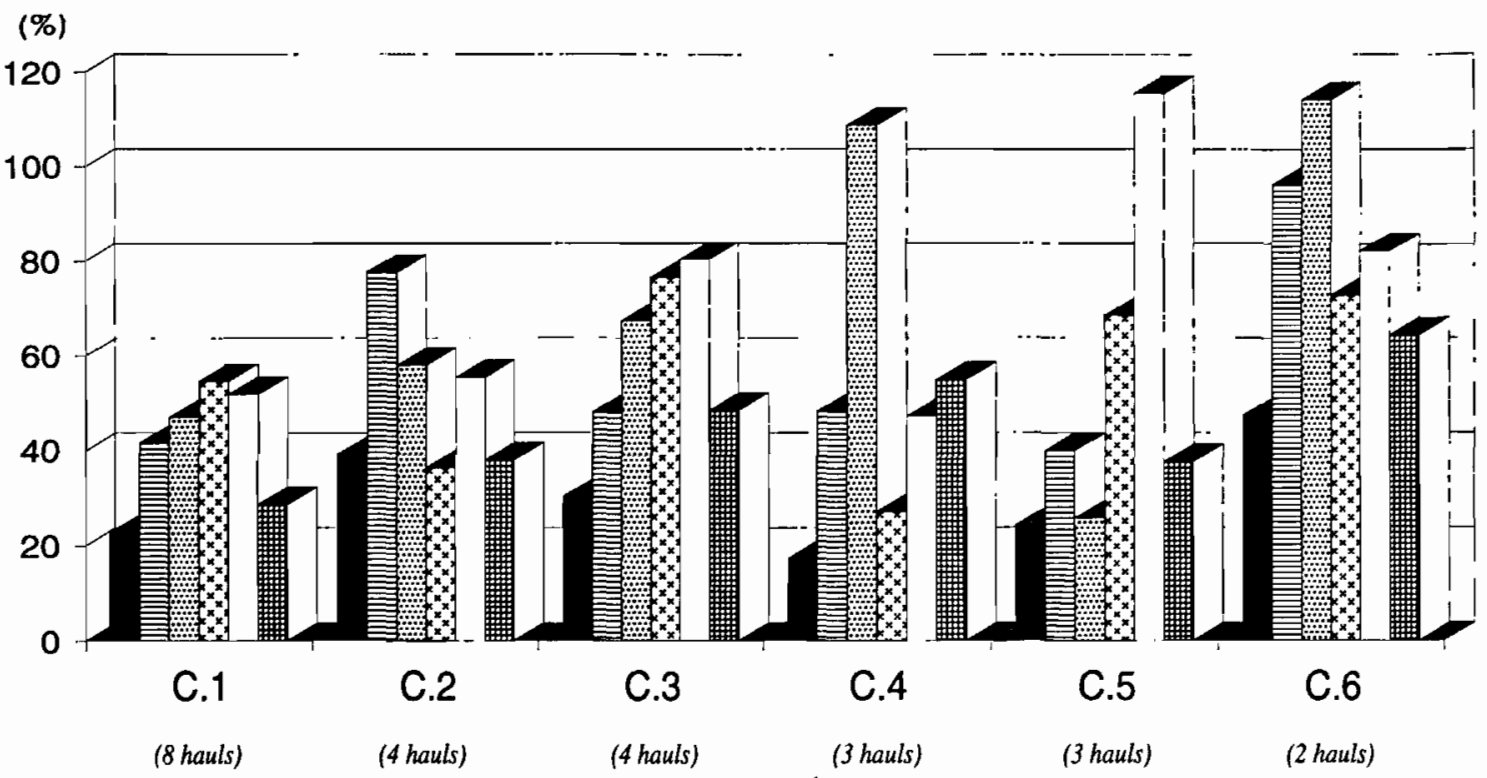

Figure 3. - Coefficients of variation (\%) of the abundance index shown in figure 2 for each species.

Table 2. - Abundance indices (tons) calculated when systematically removing one haul (upper part of the table) and when considering all of them. Average, standard deviation and coefficient of variations are based on the first eight estimates with 1 missing haul.

\begin{tabular}{|c|c|c|c|c|c|c|c|}
\hline $\begin{array}{l}\text { Haul } \\
\text { missing } N^{\circ}\end{array}$ & Sardine & Anchovy & Sprat & $\begin{array}{c}\text { Horse } \\
\text { mackerel }\end{array}$ & Mackerel & $\begin{array}{l}\text { Other } \\
\text { species }\end{array}$ & Total \\
\hline 31 & 94 & 1808 & 405 & 30 & 82 & 262 & 2681 \\
\hline 33 & 79 & 1822 & 341 & 31 & 129 & 270 & 2672 \\
\hline 34 & 99 & 1425 & 442 & 24 & 159 & 328 & 2477 \\
\hline 35 & 89 & 1771 & 268 & 26 & 119 & 288 & 2561 \\
\hline Considering 8 hauls & 87 & 1707 & 371 & 26 & 131 & 289 & 2611 \\
\hline Average & 88 & 1701 & 374 & 27 & 132 & 290 & 2612 \\
\hline Standard deviation & 17 & 155 & 57 & 5 & 24 & 32 & 96 \\
\hline Coefficient of variation & 20 & 9 & 15 & 20 & 18 & 11 & 4 \\
\hline
\end{tabular}

with fluctuations from one species to another, less pronounced for the dominant anchovy.

\section{Influence of particular hauls (table 2)}

The position of the identification hauls seems to have a greater effect on the estimate by species than the number of hauls. To check the contribution of each haul in such an area, eight biomass estimates have been calculated using only 7 hauls, i.e. by removing one haul systematically from the biomass calculations. These new estimates show that one haul may induce significant variations. For mackerel, sardine and sprat, estimates may vary by a factor of 2 . On another hand, anchovy estimates are more stable, ranging from $1425 \mathrm{t}$ to $1856 \mathrm{t}$. The horse mackerel results are not really significant because this species is generally poorly represented in this area.

This peculiarity may be explained by the lively behaviour of such species like mackerel and sardine which are usually aggregated in big shoals, in mid water column and characterised by avoidance reactions to vessels or fishing gears in this area at this season.

\section{CONCLUSION}

This investigation carried out on restricted spatial and temporal scales shows that an increase in the number of transects does not necessary increase the accuracy of a global biomass estimate. On another hand, if species compositions from trawl samples are used to split the biomass into species when computing 
abundance indices by acoustics, the number of hauls and their location appear predominant under spatiallystructured community compositions. Indeed, the variability of biomass estimates by species in this study seems to increase when lively species as mackerel or sardine are concerned, which stress the need of previous catchability studies. Nevertheless, this study suggests that sampling strategy of identification hauls may be as important as the acoustic surveying strategy, at least when mixed populations are concerned.

\section{Acknowledgements}

This research was partially financed by the Commission of the European Communities within the framework of the EEC research program $n^{\circ}$ MA 2495 . I wish to thank particularly Dr. Y. Simard who greatly contributed to improving the manuscript and C. Scalabrin for her helpful comments.

\section{REFERENCES}

Anonymous 1983. Report of the 1983 planning group on ICES - coordinated herring and sprat acoustic survey. ICES, CM 1983/H: 12.

Cochran W. G. 1977. Sampling techniques. John Wiley ed. New York, $3^{\text {rd }}$ ed 428 p.

Cushing D. H. 1977. Observations on fish shoals with the ARL scanner. Rapp. P.-v. Réun. Cons. Int. Explor. Mer. 170, $15-20$.

Diner N., R. Le Men 1983. Évaluation acoustique des stocks de poissons pélagiques dans la partie sud du golfe de Gascogne en avril-mai 1983. ICES, CM 1983/H: 44, 12 p.

Diner N., A. Weill, J. Y. Coail, J. M. Coudeville 1990. INES/MOVIES: $A$ new acoustic data acquisition and processing system. $1^{\text {er }}$ congrès français d'acoustique, Lyon, avril 1990. P. Filippi, M. Zakkaria, eds. J. Phys. Paris, suppl. 51, C2, 939-942.

Edwards J. 1., F. Armstrong 1983. Measurement of the target strength of live herring and mackerel. FAO Fish. Rep. 300, 69-77.

Foote K. G. 1980. Importance of the swimbladder in acoustic scattering by fish: a comparison of gadoid and mackerel target strength. J. Acoust. Soc. Am. 67, 2084-2089.

Gerlotto F. 1993. Identification and spatial stratification of tropical fish concentrations using acoustic populations. Aquat. Living Resour. 6, 243-254.
Johanesson K. A., G. F. Losse 1977. Methodology of acoustic estimating of fish abundance in some UNDP/FAO resource survey projects. Rapp. P.-v. Réun. Cons. Int. Explor. Mer, 170, 296-318.

MacLennan D. N., E. J. Simmonds 1992. Fisheries acoustics. Chapman and Hall, London, 325 p.

Massé J. 1988. Utilisation de l'écho-intégration en recherche halieutique (analyse des campagnes effectuées dans le golfe de Gascogne de 1983 à 1987). Rapp. IFREMER, DRV-88030, $155 \mathrm{p}$.

Rose G. A., W. C. Leggett 1988. Hydroacoustics signal classification of fish schools by species. Can. J. Fish. Aquat. Sci. 45, 597-604.

Scalabrin C., J. Massé 1993. Acoustic detection of the spatial and temporal distribution of fish shoals in the Bay of Biscay. Aquat. Living Resour. 6, 269-283.

Vorobyov V. M., A. V. Ivanov 1981. Target strength measurements of the single fish during the echo survey. Meeting on hydroacoustical methods for the estimations of marine fish populations, Cambridge, Mass. U.S.A., 25-29 June 1979, J. R. Suomala ed.

Weill A., C. Scalabrin, N. Diner 1993. MOVIESB: an acoustic detection description software. Application to shoal species classification. Aquat. Living Resour. 6, 255-267. 